Review Article

\title{
A new concept in prophylaxis and therapy: paramunization by poxvirus inducers ${ }^{1}$
}

\author{
Anton Mayr ${ }^{2}$ and Barbara Mayr ${ }^{2}$
}

\begin{abstract}
Mayr A. \& Mayr B. 1999. A new concept in prophylaxis and therapy: paramunization by poxvirus inducers. Pesquisa Veterinária Brasileira 19(3/4):91-98. Lehrstuhl für Mikrobiologie und Seuchenlehre der Tierärztlichen Fakultät der Ludwig-Maximilians-Universität München, Veterinärstraße 13, D-80539 München, Germany.

The so-called primitive, innate or paraspecific immune system is the phylogenetically older part of the complex immune system. It enables the organism to immediately attack various foreign substances, infectious pathogens, toxins and transformed cells of the organism itself. „Paramunity“ is defined as an optimal regulated and activated, antigen-nonspecific defence, acquired through continuous active and succesful confrontation with endogenous and exogenous noxes or by means of „paramunization“ with so called „paramunity inducers“. Paramunity inducers based on different pox virus species (e.g. Baypamunò , Duphapindò , Conpind) have turned out to be effective and safe when applied with human beings as well as with animals. Pox virus inducers activate phagocytosis and NK-cells in addition to regulation of various cytokines, notably interferon a and g, IL 1, 2, CSF and TNF which comprise the network of the complex paraspecific immune system.

The results of experimental work as well as practical use in veterinary medicine have shown that paramunization by pox inducers goes far beyond the common understanding of so-called ,immuno-therapy“. They are „bioregulators“, because they have 1 . a regulatory effect on a disturbed immune system in the sense of an optimal homoeostasis, and 2 . simultaneously a regulatory effect between the immune, nervous, circulatory and hormone system. Therefore, the use of paramunization by pox inducers opens a new way of prophylaxis and therapy, not only with regard to infections, but also with regard to different other indications.
\end{abstract}

INDEX TERMS: Paramunization, paramunity inducer, pox viruses, therapy, prophylaxis.

\section{INTRODUCTION}

The terms „paramunity“ and „paramunization“ are new and thus open to discussion. The terms embrace certain new prophylactic and therapeutic measures covered by a single principle. This is both appropriate and necessary, since there are a number of new diseases which can only be partly combated by the methods of classical medicine: infectious factorial diseases, mixed infections, chronic and recurrent diseases, therapy-resistent bacterial and viral infectious diseases, tumors, immune diseases and lowered resistance

\footnotetext{
${ }^{1}$ Accepted for publication on May 5, 1998.

${ }^{2}$ Lehrstuhl für Mikrobiologie und Seuchenlehre, Tierärztliche Fakultät der Ludwig-Maximilians-Universität München, Veterinärstraße 13, D-80539 München, Germany
}

of an organism by immune-suppressive noxae or disregulation of the immune system with the known pathological consequences.

For this reason, more attention has been paid to the influence of endogenous unspecific defence potentials as a prophylactic and therapeutic concept over the past few years. Suppressives have been used for a long time to suppress immunological reactions, for example in transplantation medicine. However, the purposeful regulation and activation of endogenous unspecific defence mechanisms, especially in the antigen-nonspecific areas, is a new prophylactic and therapeutic principle.

The immune system of warm-blooded animals, especially of mammals and birds, consists of an antigen-specific part and an antigen-nonspecific part (Fig. 1). The two parts are cross-linked and so form an uniform organic system. The 


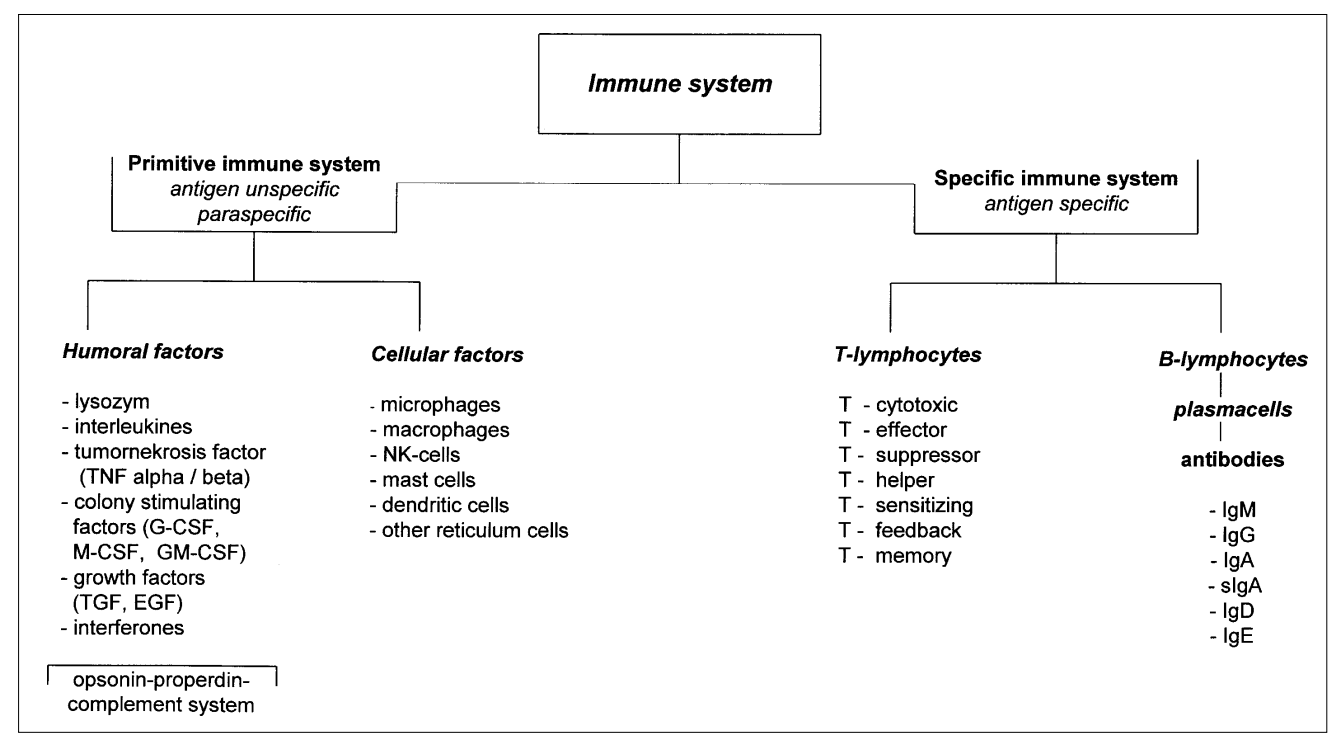

Fig. 1. Simplified diagram of the structure of the immune system.

antigen-specific mechanisms are responsible for building up immunity, while the antigen-nonspecific mechanisms are responsible for building up paramunity. Accordingly, for both historical and functional reasons the antigen-nonspecific part of the defence is known as the paraspecific (innate, primitive) immune system. Up until the present, immunology research has been mainly concerned with the antigen-specific part of the immune system, i.e. with how immunity is formed. The utilization of this defence potential led for example to the development of active and passive immunization. In contrast, the exploitation of the paraspecific activities of the immune system for prevention and therapy is still in its early stages. The paraspecific immune system makes it possible for the organism to mount an immediate defence when confronted by the most diverse foreign substances, infectious pathogens, toxins and transformed cells of the organism itself. There are patterns of close functional interplay between the paraspecific and the specific activities of the immune system, generally involving a flow of information from the paraspecific mechanisms, which react first, to the specific activities of the immune system.

Since Edward Jenner introduced protective immunization against smallpox in 1798 using a vaccine obtained from animals (cattle or horses) and based on the vaccinia virus, empirically obtained results have been reported showing that protective immunization against smallpox resulted in those vaccinated recovering surprisingly rapidly, without complications, from other infections and diseases, especially chronic and relapsing complaints, from which they happened to be suffering at the time of vaccination (Baxby 1981, Mayr 1993). In particular this applies to herpes infections of varying genesis, papilloma, chronic eczemas and pathological conditions of the ears, nose and throat. As well as this, however, it was noted, that those immunized showed a generally raised short-term level of resistance to acute ambient infections. Similar phenomena have been noted after protective immunization against various forms of animal pox. It was deduced from these findings that poxviruses or certain structural components of these viruses can positively influence the organisms ability to resist infections and tumours, on a nonspecific level. Because these nonspecific healing processes commence immediately after vaccination and develop 5 to 7 days before the specific immunity conferred by vaccination develops, as well as parallel to thereto, A.Mayr (1978) designated these nonspecific consequences of a prophylactic immunization as „paraspecific“. Accordingly, medicaments produced specifically to exploit such paraspecific effects are known as „paramunity inducer“. The condition which results of treatment by paramunity inducers is called „paramunity“.

\section{DEFINITIONS AND FUNDAMENTALS}

The paraspecific immune system is a physiological process in the daily struggle of an organism against endogenous and exogenous noxious influences. It goes into action immediately, reacts in a correspondingly non-specific manner, and may be defined as a „primary check“ of the native immune system. It's task is to bind pathogens, then to inactivate and remove them, or at the very least to prevent them from exerting any effect damaging to the organism until specific immune reactions (antibodies, immune cells) are present. The unspecific immune system possesses regulatory functions for the immune system as a whole.

The paraspecific immune system is irreplaceable not only for the lower organisms but also for the highly developed vertebrates. Primary congenital defects in this phylogenically old (innate) immune system lead to life-threatening situations. Fortunately enough, there are at present only a few examples, one of which being the Chediak-Steinbrinck-Higashi syndrome in man, which is characterized by granulocyte defects and dysfunctions of the natural killer cells (NK cells) and is usually fatal by the age of 10 (Padgett et al. 1970). Transient secondary 


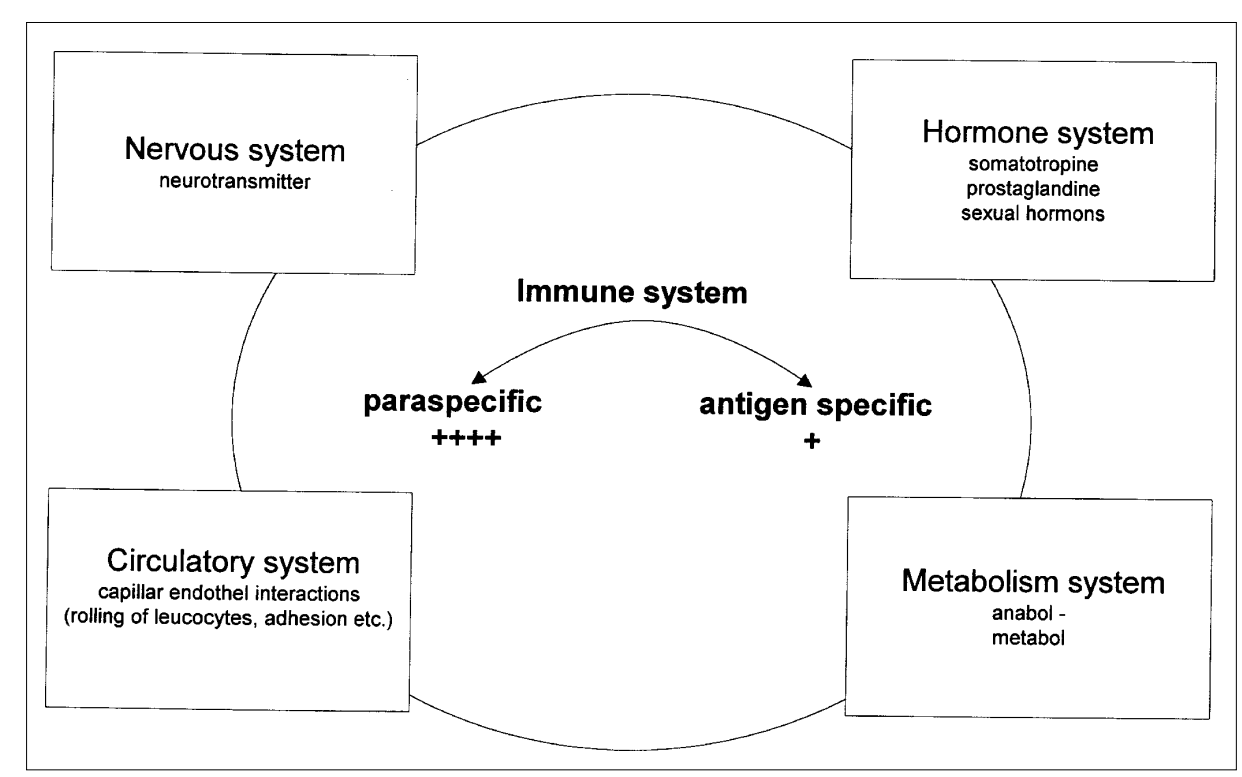

Fig. 2. Interactions of the immune system with other essential systems of the organism.

defects, on the other hand, have a higher incidence, for example in the complement system, causing impairment of phagocytosis and promoting the activation of infections with opportunistic pathogens (Büttner 1993, Finlay \& Falkow 1989, Rumyantsev 1992, Warner et al. 1988, Welsh et al. 1991).

As a result of a continuous grappling with the most exogenous and endogenous noxious influences, the organism develops an enhanced antigen-nonspecific defence, and this defence is known as paramunity.

Paramunity is the state of a well regulated and optimally functioning nonspecific defence system, combined with an enhanced defence, of limited duration, against a large number of different causative agents, antigens and other noxious influences. Just as ,immunity“ is understood to be acquired specific protection against one particular infectious disease, „paramunity“ is the acquired nonpathogen-specific and nonantigen-specific protection of an individual. This may be accompanied by an enhancement of phagocytosis rate, the function of spontaneous cell-mediated cytotoxicity (NK cells) and the activity of other lymphoreticular cells. At the same time, certain cytokines are released, and these interact both with the cellular elements and among each other. This interactions may be of both a stimulating and a suppressive nature (repressor mechanisms). The aim is to relieve dysfunctions, to rapidly raise the defence level of individual which is not pathogen- or antigen-specific, to eliminate any immunosuppression or immunological weakness that has arisen through the effects of stress or otherwise (i.e. through medication). This closely enmeshed biosystem of immunity, which reacts in stages, and involves receptor, effector and target cells, is furthermore closely bound up with the hormonal and nervous systems (Fig. 2).

Paramunity is exploited by paramunization. Paramunization is set in train 1.) as the result of a physiological process in the daily struggle of an organism against endogenous and exogenous noxious influences, and 2.) by the use of medication with paramunity inducers. The paramunization is an imitation of natural reactions under controlled conditions with much higher efficacy and safety (Mayr 1997).

Paramunity inducers are biological products similiar to vaccines which have a paraspecific effect and which are nonimmunizing. Paramunity inducers must meet strict requirements of nonharmfullness and efficacy, which sharply differentiates them from what are called immune stimulants. The most important criteria are given in Table 1. At present these requirements are fullfilled only by paramunity inducer made from pox viruses. Poxvirus paramunity inducer consist of attenuated (avirulent) and inactivated pox viruses, virus components, i.e. subunits, especially derived from the envelope of pox viruses. In contrast to vaccines poxvirus inducers do not directly interact with the antigen-specific part of the immune system, but with the non-specific i.e. paraspecific part of the immune system. The result is an optimal regulation of the highly complex immune system through activation of macrophages, NK-cells and lymphoreticular cells as well as through the production, release and

Table 1. Criteria for paramunity inducers
1. Definable active agent
2. Standardizable
3. Dose effect
4. No toxicity and teratogenicity, pyrogen-free
5. No residues
6. Effective only via mobilization of body's own biosystems
7. Ineffective in vitro without cellular components
8. Can be combined with other medicines and vaccination substances
9. Active preventively and therapeutically, systemically and locally
10. Nonimmunizing 


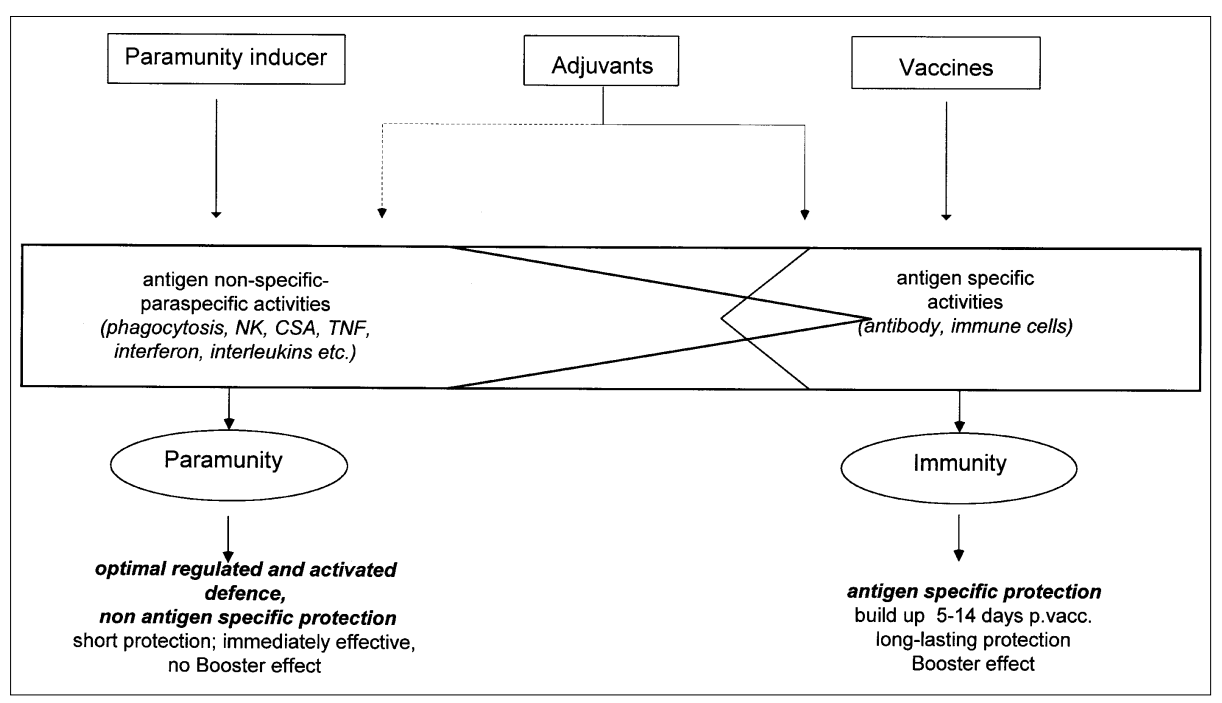

Fig. 3. Application of the immune system in medicine.

interaction of many cytokines (cytokine cascade), such as interferon, interleukin (IL-1, IL-2, IL-12) CSF, TNF and several others (Fig. 3).

More than 20 interacting protein complexes within the viral envelope, such as the adsorption protein, the fusion protein and various further structural proteins are responsible for the paramunizing effect. Meanwhile some of these proteins could be isolated and the corresponding parts of the DNA could be expressed in a suitable system. Each protein component by its own has only a very low efficacy detectable in ,in vitro“-systems, and only marginal effects in ,in vivo“-experiments (Czerny \& Mahnel 1990, Büttner et al. 1995). For the required complex efficacy and for the safety of humans and animals, however, the non-immunizing protein complexes in the envelope of the intact virus particles are necessary, true to the cybernetic idea that ,the total is more than the sum of its parts". The reason for the complex efficacy is the so-called "system-theory“ based on the interactions and connections of the single parts.

Paramunity inducers made from pox viruses are novel drugs which contain non-immunizing, intact connected antigenic structures of attenuated and inactivated strains of pox viruses and which are intended for paramunization in man and animals. In contrast to the antigen-specific vaccination the paramunization can be used for prophylaxis and also for therapy to prevent or regulate dysfunctions of the immune system in order to optimise the non-specific acquired resistance. The paramunization supports, for example, the stimulation of TH-1 subpopulations, and thereby prevents the production of $\mathrm{TH}-2$ subpopulations which are known to be involved in the induction of the immediate hypersensitivity (antibody-mediated allergy).

The pox paramunity inducers are metabolised immediately and do not leave residues. The duration of efficacy is short (about up to 12 days). A possible minimal antibody production detectable by way of ELISA tests emerging after repeated and continuous application does not interfere with the efficacy of the drug.

In veterinary medicine, paramunity inducers have been produced from purified, attenuated and inactivated avipox and parapox viruses. These paramunity inducers are registered in the European countries as Duphapindò and and Duphamunò (PIND-AVI) and as Baypamunò (PIND-ORF) for virtually all species of farm and domestic animals. Paramunity inducer PIND-AVI is prepared from attenuated avipox virus, strain HP 1, and paramunity inducer PIND-ORF is prepared from an attenuated parapox virus, strain D 1701. The attenuated viruses are rendered inactive in a manner known per se, e.g. by gradiation or chemical means such as treatment with b-propiolactone.

Pox inducers can be used as drugs, prepared from a single pox virus, as well as preparations made from different poxvirus species, e.g. avian and parapox viruses or other combinations (multipotent paramunity inducers, e.g. Conpind; Europ.Patent No. 0669 133; Dtsch.Patent No. 4405 841). It was unexpectedly found that combining pox virus components in the multipotent paramunity inducers does not result in a decrease in, let alone loss of, the respective paramunizing activities of the individual poxvirus components. Instead it was seen that combining the poxvirus compoments derived from various poxvirus strains or species in the multipotent paramunity inducers brings about not only an additive or supplementary effect, but a potentiation of the respective paramunizing action. Experiments have shown that the action of the multipotent paramunity inducers combined from poxvirus compenents far exceeds their respective individual actions. This phenomenon could not have been predicted, and in terms of their potency and their paramunization-related activities it enhances the paramunity inducers as compared with conventional preparations from a single component. Another finding is that the multipotent paramunity inducers have virtually no immunogenic properties, but do have very strong 
paramunization properties, as a result of which they can safely be administered on a repeated or continuous basis.

There exists a competitive situation between the epitopes of the structural proteins of the poxviruses responsible for paramunization and those responsible for immunization. The steeper the decline in activity on the part of the epitopes responsible for antigen-specific immunization, the bigger is the increase in paraspecific activity. This is attested by the following two observations:

1. Attenuation over several hundred passages in cell cultures causes the immunizing properties of poxviruses to decrease, whilst the paraspecific activities not only increase but in the case of certain pox strains only appear after attenuation.

2. Inactivation of the poxviruses suited to preparation of the paramunity inducers, preferably by irradiation, or by chemical treatment, e.g. with $g$ propiolactone under specific conditions, causes the poxviruses to lose their immunizing properties whereas their paramunizing activities increase.

The combinations of poxvirus components with different activities in a single drug are suited for use as multipotent paramunity inducers in both human and veterinary medicine.

The term „poxvirus component" covers a large number of viral structures derived from poxviruses with paramunizing properties, for example viable (i.e. capable of multiplication) or inactivated, attenuated poxviruses, individual viral polypeptides obtained by biochemical or immunochemical methods from cultures that have been infected with the poxviruses or recombinant viral polypeptides (Table 2 ).

\section{PRECLINICAL STUDIES}

The above described poxvirus paramunity inducers Duphapindò, Baypamunò and Conpind were tested in different test models for their efficacy and safety (Mayr \& Mayr 1995, Mayr 1997).

The investigations on the „systemic level“ (parenteral application of pox-inducers to man and animals) have proved

Table 2. Demonstration of the potentiating effect on the efficacy of a combined paramunity inducer in the VSV-baby mouse challenge test

\begin{tabular}{cc}
\hline Type of paramunity inducer & $\begin{array}{c}\mathrm{EU} / \mathrm{ml} \\
(1: 8 \text { predilution })\end{array}$ \\
\hline PIND-AVI & $160-320$ \\
PIND-ORF & $320-640$ \\
ORF-Protein 4D9 & $40-80$ \\
Combined paramunity inducer & $1280-2560$ \\
PIND-AVI + ORF 4D9 &
\end{tabular}

the preparations to be harmless and surprisingly effective with regard to certain indications. The efficacy was demonstrated for example in viral challenge infections in mice (reduction of mortality), bacterial wound infections (rapid healing), radiation-induced murine osteosarcoma and various other murine carcinoma (reduction of tumour growth and metastasis), radiation-induced immunosuppression in mice (recovery of the immune system). Above that pox inducers prevent the transport-induced increase of cortisol level in horses, increase the levels of interferon a in periphereal blood (man, piglets, mice), prime leucocytes (pig) and have a regulative effect on the ,rolling“ of leucocytes after endotoxinchallenge (leucocyte/endothel interaction in mice) (Schmitt 1995). The clinical data correlate to laboratory parameters apt to serve as proof for the efficacy. The challenge models (VSV, Aujeszky) verify a dosis- efficacy relationship.

The evaluation of the efficacy of the pox inducers in isolated blood- and liver-cells respectively cell cultures (cellular „in vitro“ level) provide a unified picture: increase of the phagocytosis (uptake and respiratory burst (FACS), clearance and phagocytosis of Ps.aeruginosa in isolated perfused livers of germ-free rats), the thymidin metabolism in liver cells, the NK-cells (spontaneous natural cytotoxicity) and stimulation of lymphatic cells (lymphoma, hybridoma) to release cytokines.

The investigations in the „cytokine release“ illustrate that pox inducers promote the release respectively the production of diverse cytokines important for the regulation of the immune system. This has been proved for interferon a and $\mathrm{g}$, the interleukines 1, 2 and 12 as well as for CSF and TNF.

To conclude, a regulative effect is ascribed to the poxvirus inducers in the network of paraspecific defence in regard to stimulating as well as inhibiting effects. The endogenous medication by way of pox inducers (paramunization) is diametrically opposed to the exogenous application of cytokines.

The described investigations confirm that results of ,in vitro" or "ex vivo-in vitro" tests allow extrapolations as to the clinical efficacy of pox inducers for both therapy and prophylaxis. As matter of general principles, it is true for biopreparations as well that the preclinical demonstration of efficacy cannot be automatically equated with the prophylactic and therapeutic effect. For the inducers obtained from attenuated poxvirus strains, however, the preclinical demonstrations of efficacy are clinically relevant according to the broad spectrum of all the test results so far obtained. The clinical relevance, or the evaluation of the results of in vitro and ex vivo-in vitro investigations for assessing the clinical efficacy of pox inducers, is scientifically valuable and can be experimentally proved. The most important concepts for comparison are the following:

\footnotetext{
- homologous results in vitro, ex vivo-in vitro and clinically (prophylaxis, therapy) in farm animals, pets and humans;

- homology of cellular (phagocytosis, NK activity) and soluble components (interferon, interleukins, tumor necrosis factor, colony stimulating factor) in humans and animals;

- homology of both phylogenetic and ontogenetic development of both the complex paraspecific and antigen-specific immune systems;

- equal efficiency and safety in humans, pets, farm animals and experimental animals;

- paraspecific efficacy demonstrable for all genera of pox viruses;

- homology of immunological, endocrine and nervous control mechanisms (compound system);

- historical reports from the age of smallpox vaccinations since Edward Jenner 1796.
} 


\section{CLINICAL STUDIES}

The pox inducers Duphamunò , Duphapindò and Baypamunò have been registered in Europe for many years. They were succesfully used on a wide variety of pets and farm animals with different indications. The abundance of publications on this topic make a general review in this place impossible. The following examples in Table 3 and 4 will prove the correctness of the above mentioned concept in regard of the extrapolation of in vitro and ex vivo-in vitro obtained results for the clinical efficacy of pox inducers.

Table 3. Clinical use of pox inducer for paramunzation in veterinary medicine (farm animals)

\begin{tabular}{|c|c|c|}
\hline Species & Disease/disease complex & Reference \\
\hline Horse & $\begin{array}{l}\text { Infectious diseases of the respiratory tract } \\
\text { Transport induced increased cortisol level }\end{array}$ & $\begin{array}{l}\text { Strube et al. } 1989 \\
\text { Mayr \& Siebert } 1990\end{array}$ \\
\hline Cattle & $\begin{array}{l}\text { Infectious bovine rhinotracheitis (IBR) } \\
\text { Bovine enzootic bronchopneumonia } \\
\text { Mastitis } \\
\text { Crowding associated infectious } \\
\text { respiratory disease }\end{array}$ & $\begin{array}{c}\text { Castrucci et al. } 1995 \\
\text { Strube et al. } 1989 \\
\text { Mayr } 1996 \\
\text { Ziebel et al. } 1997\end{array}$ \\
\hline Pig & $\begin{array}{l}\text { Neonatal morbidity } \\
\text { Enzootic pneumonia } \\
\text { MMA-complex of sows } \\
\text { Reproductive performance of gilts }\end{array}$ & $\begin{array}{l}\text { Mayr } 1986 \\
\text { Hammerl et al. } 1995 \\
\text { Kyriakis et al. } 1996\end{array}$ \\
\hline Birds & $\begin{array}{l}\text { Flight performance of homing pigeons, } \\
\text { Secretion of coccidial oocystes }\end{array}$ & $\begin{array}{c}\text { Haas } 1986 \\
\text { Haas \& Kösters } 1987 \\
\text { Richter } 1983(29)\end{array}$ \\
\hline
\end{tabular}

Table 4. Clinical use of pox inducer for paramunzation in veterinary medicine (pet animals)

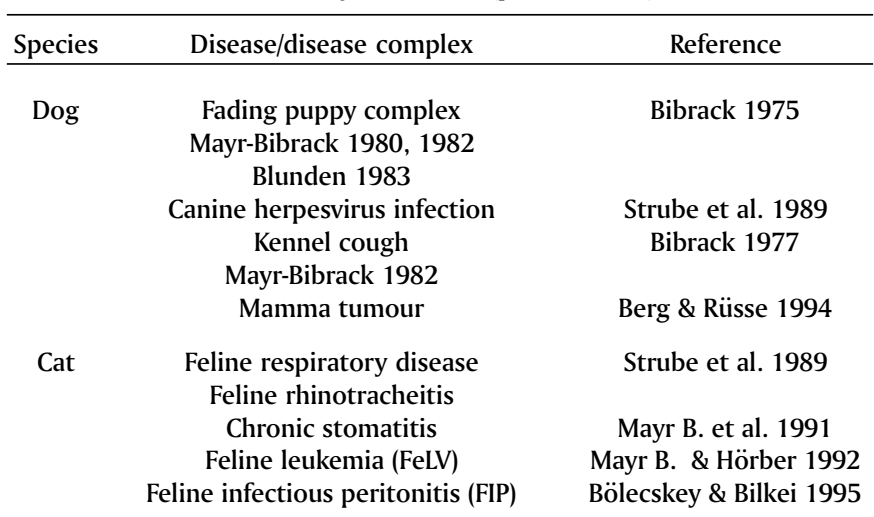

\section{CONCLUSIONS}

Indications

The experience in practice has demonstrated that paramunization with poxvirus inducers is a new concept in as well prophylaxis as therapy. The most important indications for prophylactic use are:

- rapid activation of the neonate paraspecific part of the immune system; - before expected stress situations (avoidance of stress-induced damages);

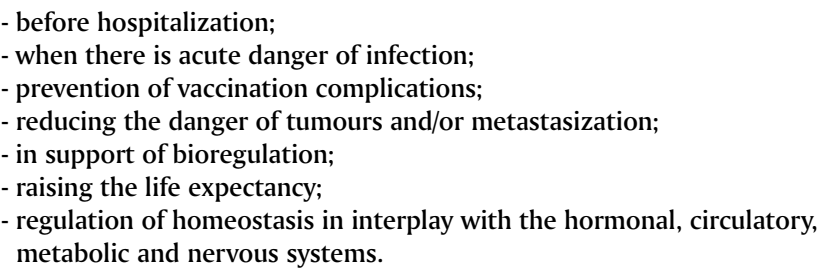

Paramunity inducers obtained from poxviruses are particularly suitable for therapeutic use in the follwing instances:

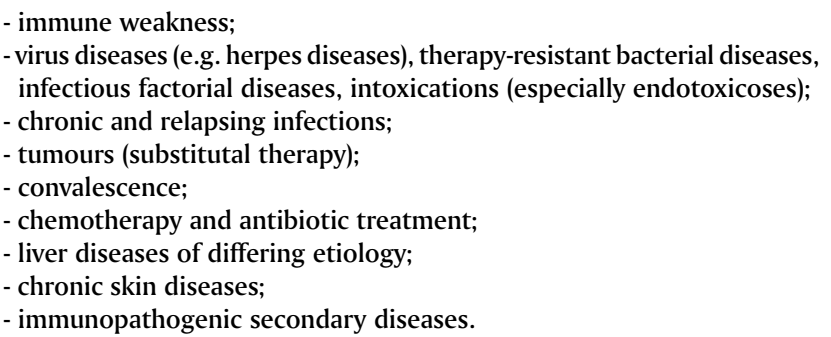

Bioregulatory activity

The results of as well experimental work as practical use in veterinary medicine have shown that treatment with pox inducers goes far beyond the common understanding of socalled "immunotherapy". They are "bioregulators", because pox inducers have a regulatory effect on a disturbed immune system not only in the sense of increasing or stimulating reduced or suppressed activities but also in the sense of decreasing pathologically enhanced immunoparameters to the optimal physiological range. For understanding the regulatory effect of pox inducers in the sense of bioregulation which takes place between the immune, hormon, metabolic, circulatory and nervous systems, it $\mathrm{x}$ inducers. This may, for example, occur because the number or activity of specific effector cells (e.g. macrophages, leukocytes, T-cells, NK-cells) rises or drops, or the production of cellular and humoral mediators (e.g.IL 1, 2, interferons, TNF etc.) increases or decreases. Each organism reacts differently and individually depending on the functional state of its defence system at the beginning of the treatment with the pox inducer. For example, after the treatment of the patient with pox inducers the number of leucocytes may increase, while on the other hand the number of NK-cells in their activity remains the same or even decreases. For the compensation of dysregulations of the immune system it is not necessary that all immunological parameters be stimulated or suppressed simultaneously, since only existing deficiencies or excessive values are equilibrated. The individualisation into the physiological standard range by the treatment with pox inducers is therefore a completely new finding. Since an intervention of pox inducers in the individual defence system also simultaneously has a regulatory effect on the nervous, hormone, (circulatory and metabolism) systems, pox inducers should not be defined as immuno-regulators, rather it is suggested that they be considered bioregulators. Such a bioregulator which is harmless even when used in high overdoses, which does not influence the physiological „nor- 
mal values" of the immune system and which has a regulatory effect in the case of dysfunction in the sense of a physiological normalisation, i.e. stabilising or restoring the immune system in its entire functionality, so far does not exist in medicine.

\section{Application and dosage}

Therefore, pox inducers are particularly useful for the prophylactic and metaphylactic application in patients having a dysregulated immune system, for example in case of immunodefects of different genesis, such as after an immunosuppressive therapy, in case of immunosuppressive primary disease, or by exogenic influences, like stress situations, unusual strains, long journeys, acute infections in the environment. For the prophylactic paramunization normally 2 to 3 injections of a pox inducer preparation are sufficient given on consecutive days shortly before expected strain. Metaphylactic or therapeutic doses of pox inducers should be given at least 3 days or until a clear decline of clinical symptoms. After serious illnesses, in particular after infectious diseases, convalescence should be supported by 2 to 3 injections per week of a pox inducer until complete rehabilitation.

Limitations of paraspecific immune system. The limits of the paraspecific immune system and thus of paramunization are found in genetic defects such as the Chediak-Steinbrinck-Higashi-syndrome (see above). When there is a total primary absence of, or some form of transient secondary damage to, the paraspecific immune system, the organism, in contrast to a deficiency in the formation of antibodies or immune cells, has no chance. Transgenic animals, such as nude mice, which possess no T- or Blymphocytes, can quite well live in a germ-laden environment if their nonspecific immune system is functioning (Welsh et al. 1991); if the system is absent, their chances of survival are virtually nil. Corresponding to this, the success of a paramunization as well depends entirely on the residual "responsiveness" of the paraspecific immune mechanisms.

For the substitution of defined immune deficiencies the avaible methods are exogenic medication with cytokines or adoptive cell transfer. It is hoped that this will open up new paths for medical indications or principles of treatment. Thus, for example, the exogenic use of recombined interleukin 2 preparations is of particular benefit to patients with melanoma and renal carcinoma, in whom the primary disease can at least be kept under control for a certain time with this treatment method. Meanwhile, however, even here there is an increase in the number of reports of serious side effects, as with the administration of exogenic interferon. Generally speaking the clinical use of individual cytokines is accompanied by more or less toxic effects, and it harbours the danger of upsetting existing endogenous regulatory mechanisms. As far as is known at present, the least dangerous method is the exogenic administration of cytokines G-CSF and GM-CSF (colony stimulating factors) and of interleukin 2 and 3 individually or in combination. By contrast, interleukin 1,6 and $8, T N F$ and interferon should be used with great caution.

\section{REFERENCES}

Albus K. \& Zimmermann E. 1993. Bewertung eines Paramunitätsinducers zur Verhinderung transportbedingter Erkrankungen bei Zuchtkaninchen. Kleintierpraxis 38:44.

Baxby D. 1981. Jenner's smallpox vaccine. Morrison \& Gibb Ltd, London.

Berg G. \& Rüsse M. 1994. Der Einsatz von Baypamun HKÒ in der Mammatumorbehandlung der Hündin. Tierärztl. Umschau 49:476-480.

Bibrack B. 1975. Aktive Interferonisierung: eine neue Möglichkeit der Bekämpfung des infektiösen Welpensterbens. Kleintierpraxis 20:258-263.

Bibrack B. 1977. Prophylaxe des virusbedingten Respirationssyndroms des Hundes. Zbl. Vet. Med., Beiheft 28 (12.Kongreßbericht der DVG).

Blunden A.S. 1983. The „fading puppy complex“: an assesment of a paramunity inducer as a means of control. Vet. Rec. 113:201.

Bölecskei A. \& Bilkei G. 1995. Langzeitstudie über behandelte FIP-verdächtige Katzen. Tierärztl. Umschau 50: 721-728.

Büttner M. 1993. Principles of paramunization: option and limits in veterinary medicine. Comp. Immun. Microbiol. Infect. Dis. 16:1-10.

Büttner M., Czerny C.-P., Lehner K.H. \& Werz K. 1995. Interferon induction in peripheral blood mononuclear leukocytes of man and farm animals by poxvirus vector candidates and some poxvirus constructs. Vet. Immunol. Immunpath. 46:237-250.

Castrucci G., Ferrari M., Osburn B.I., Frigeri F., Barreca F., Tagliati S. \& Cuteri V. 1995. The use of a non-specific defence mechanism inducer in calves exposed to bovine herpesvirus- 1 infection: preliminary trials. Comp. Immun. Microbiol. Infect. Dis. 18:85-91.

Czerny C.-P. \& Mahnel H. 1990. Structural and functional analysis of orthopoxvirus epitopes with neutralizing antibodies. J. Gen. Virol. 71:2341.

Finlay B.B. \& Falkow S. 1989. Common themes in microbial pathogenicity. Microbiol. Rev. 53:210.

Haas L. 1986. Die Auswirkung des Paramunitätsinducers PIND-ORF auf die Flugleistung sowie auf die Ausscheidung von Kokzidienoozysten von normalen und immunsupprimierten Brieftauben (Columba livia Gmel. 1789 var. dom.). Med. Vet. Diss., München.

Haas L. \& Kösters J. 1987. Die Auswirkungen des Paramunitätsinducers PINDORF auf die Flugleistung von gesunden und erkrankten Brieftauben (Columba livia Gmel. 1789 var. dom.) J. Vet. Med. B 34:305-309.

Hammerl J., Wolf G. \& Berner H. 1995. Klinische Untersuchungen zur Wirkung des Paramunitätsinducers BaypamunÒ als Prophylaxe beim MMA-Komplex der Sau. Tierärztl. Umschau 50:383-386.

Kyriakis S.C., Alexopoulos C., Giannakopoulos K., Tsinas A.C., Saoulidis K., Kritas S.K. \& Tsiloyiannis V. 1996. Effect of paramunity inducer on reproductive performance of gilts. J. Vet. Med. A 43:483-487.

Mayr A. 1978. Prämunität, Prämunisierung und paraspezifische Wirkung von Schutzimpfungen. Münch. Med. Wschr. 120:239-242.

Mayr A. 1986. Nutzung der Paramunisierung in der Schweinehaltung. Tierärztl. Praxis 14:237-244.

Mayr A. \& Siebert M. 1990. Untersuchungen über die Wirksamkeit des Paramunitätsinducers PIND-ORF auf den durch Transportstress ausgelösten Kortisolanstieg beim Pferd. Tierärztl. Umschau 45:677-682.

Mayr A. 1993. The paraspecific immune defence system: potentials and limitations. Anim. Res. \& Developm. 38:60-80.

Mayr A. 1996. Nutzung der Immunisierung und Paramunisierung zur Prophylaxe und Therapie von Mastitiden. Prakt. Tierarzt 3:202-208.

Mayr A., Ahne W. \& Vilsmeier B. 1997. Evaluation of the results of in vitro and ex vivo-in vitro experiments for the assessment of paramunity inducers obtained from pox viruses. Anim. Res. Develop. 45:7-27.

Mayr B., Deininger S. \& Büttner M. 1991. Behandlung der chronischen Stomatitis der Katze durch die lokale Paramunisierung mit PIND-ORF. J. Vet. Med. B 38:78-80.

Mayr B. \& Hörber D. 1992. Paramunisierung FeLV-positiver Katzen - ein Bericht aus der Praxis. Kleintierpraxis 37:515-518.

Mayr B. \& Mayr A. 1995. Zum derzeitigen Stand der präklinischen Forschung 
über die Wirksamkeit und Unschädlichkeit von Paramunitätsinducern aus Pockenviren. Eine Literaturstudie. Tierärztl. Praxis 23:542-552.

Mayr-Bibrack B. 1980. Paramunisierung von Neugeborenen. Prakt. Tierarzt 61:715-718.

Mayr-Bibrack B. 1982. Neue Bekämpfungsverfahren gegen Virusinfektionen des Hundes: Kombinationsvaccine gegen den Zwingerhusten und Paramunisierung gegen das infektiöse Welpensterben. Prakt. Tierarzt 63:11-18.

Padgett G.A., Holland J.M., Prieur D.J., Davies W.C. \& Gorham J.R. 1970. The Chediak-Higashi-Syndrome: a review of the disease in man, mink, cattle and mice, p. 1-12. In: Animal Models for Biomedical Research. III. Nat. Acad. Sci., Washington, D.C.

Richter R. 1983. Untersuchungen zur Steigerung der Immunantwort durch den Paramunitätsinducer PIND-ORF bei Geflügel. Med. Vet. Diss., München.

Rumyantsev S.N. 1992. Observations on constitutional resistance to infection. Immunology Today 13:184.

Schmitt M. 1995. Untersuchung der biologischen Funktion von L-, E- und P-
Selektin sowie Conpind AO-012 auf die Leukozyten/Endothel-Interaktion bei Endotoxinämie: eine intravitalmikroskopische Untersuchung an der Maus. Vet. Med. Diss., München.

Strube W., Thein P., Kretzdorn D. \& Grunmach J. 1989. Baypamun: new possibilities for the control of infectious diseases in domestic animals. Vet. Med. Rev. 60:3-15.

Warner C.M., Rothschild M.F. \& Lamont S.J. 1988. The molecular biology of the major histocompatibility complex of domestic animal species. IS Iowa State University Press, Ames.

Welsh R.M., Brubaker J.O., Vargas-Cortes M. \& Donell C.L.O. 1991. Natural Killer (NK) cell response to virus infections in mice with severe combined immunodeficiency. The stimulation of NK cell-dependent control of virus occur independently of T and B cell function. J. Exp. Med. 173:1053.

Ziebel K.-L., Kretzdorn D., Auer S., Failing K. \& Schmeer N. 1997. The use of Baypamun $\mathrm{N}$ in crowding-associated infectious respiratory disease: efficacy of Baypamun N (freeze dried product) in 2-week-old veal calves. J. Vet. Med. B 44:415-424. 